\title{
Study of Various Slanted Air-gap Structures of Interior Permanent Magnet Synchronous Motor with Brushless Field Excitation
}

\author{
Seong Taek Lee ${ }^{1}$ \\ Member, IEEE \\ ${ }^{1}$ Hyundai Ideal Electric Co. \\ 330 E. 1 st St. \\ Mansfield, OH 44902, USA \\ slee@idealelectricco.com
}

\author{
${ }^{2}$ University of Tennessee \\ 414 Ferris Hall \\ Knoxville, TN 37996, USA \\ tolbert@utk.edu
}

\author{
Leon M. Tolbert ${ }^{2,3}$ \\ Senior Member, IEEE \\ ${ }^{3}$ Oak Ridge National Laboratory \\ 2360 Cherahala Boulevard \\ Knoxville, TN 37932, USA
}

\begin{abstract}
${ }^{1}$ Abstract -- This paper shows how to maximize the effect of the slanted air-gap structure of an interior permanent magnet synchronous motor with brushless field excitation (BFE) for application in a hybrid electric vehicle. The BFE structure offers high torque density at low speed and weakened flux at high speed. The unique slanted air-gap is intended to increase the output torque of the machine as well as to maximize the ratio of the back-emf of a machine that is controllable by BFE.

This irregularly shaped air-gap makes a flux barrier along the d-axis flux path and decreases the d-axis inductance; as a result, the reluctance torque of the machine is much higher than a uniform air-gap machine, and so is the output torque. Also, the machine achieves a higher ratio of the magnitude of controllable back-emf. The determination of the slanted shape was performed by using magnetic equivalent circuit analysis and finite element analysis (FEA).
\end{abstract}

Index Terms - air gaps, inductance, permanent magnet machine, synchronous motors, torque.

\section{NOMENCLATURE}

BFE brushless field excitation

IPMSM interior permanent magnet synchronous motor

FEA finite element analysis

PM permanent magnet

\section{INTRODUCTION}

The interior permanent magnet synchronous motor (IPMSM) is currently used by many leading auto manufacturers for hybrid electric vehicles (HEVs) because the power density for this type of motor is high compared with induction motors and switched reluctance motors. However, the primary drawback of the IPMSM is the limited high-speed operation caused mainly by the high back-emf from the permanent magnets (PM) and the low d-axis inductance value [1-2].

To avoid the primary drawbacks of the IPMSM, a brushless field excitation (BFE) structure is introduced [3-6].

\footnotetext{
${ }^{1}$ The submitted manuscript has been authored by a contractor of the U. S. Government under contract no. DE-AC05-00OR22725. Accordingly, the U.S. Government retains a nonexclusive, royalty-free license to publish or reproduce the published form of this contribution, or allow others to do so, for U. S. Government purposes. Research sponsored by the Oak Ridge National Laboratory managed by UT-Battelle, LLC for the U. S. Department of Energy under contract DE-AC05-00OR22725.
}

This structure offers two advantages: (1) high torque per ampere per core length at low speed as a result of using flux that is enhanced by increasing DC current to a fixed excitation coil, and (2) flux that is weakened at high speed by reducing current to the excitation coil.

To maximize these advantages, a slanted air-gap structure is analyzed. Although the irregularly shaped air-gap reduces the air-gap flux (reduced PM torque), it also makes a flux barrier only on the d-axis flux path and decreases the d-axis inductance (increased reluctance torque). Additionally, the overall waveform of the reluctance torque versus input phase current angle will be shifted from $135^{\circ}$ to $90^{\circ}$ which is the angle of the maximum PM torque position. Therefore, the total output torque of the machine could increase to compensate for the decreased PM torque [7]. Achieving a higher ratio of the magnitude of the back-emf between the lowest and the highest excited condition is another benefit of the slanted air-gap structure.

This paper describes the process to obtain the best slanted air-gap shape for the maximum output torque and controllable back-emf ratio.

\section{THEORETICAL APPROACH TO SLANTED AIR-GAP}

Without considering the cross-coupled flux linkage between the d- and q- axes, the reluctance torque equation is expressed as [8-11]:

$$
T_{r}=\frac{m}{2} p\left(L_{d}-L_{q}\right) i_{d} i_{q}=\frac{m}{2} p\left(\lambda_{d, i d} i_{q}-\lambda_{q, i q} i_{d}\right),
$$

where $m$ is the number of phase conductors, $p$ is the number of pole pairs, $L$ is inductance, and $i$ is the instantaneous current. The subscripts $d$ and $q$ indicate the d-axis and q-axis, respectively. In the right side of (1), $\lambda_{d, i d}$ is the d-axis flux linkage caused by d-axis current, and $\lambda_{q, i q}$ is the q-axis flux linkage caused by q-axis current. Since mainly q-axis current determines the total output torque, the reluctance torque will be increased when $\lambda_{d, i d}$ is small and $\lambda_{q, i q}$ is high. Slanted airgap is considered for this purpose.

Fig. 1 shows the example rotor with the slanted air-gap. The dashed lines in the figure are the original d- and q-axis when the rotor has a uniform air-gap. To increase the 
reluctance torque, the new d- and q-axis will be rotated with the angle of $\alpha$, as shown by the solid line in Fig. 1. Then, the new reluctance torque equation will be

$$
T_{r}=\frac{m}{2} p\left(L_{d^{\prime}}-L_{q^{\prime}}\right) i_{d^{\prime}} i_{q^{\prime}}=\frac{m}{2} p\left(L_{d^{\prime}}-L_{q^{\prime}}\right) i_{d+\alpha} i_{q+\alpha} .
$$

where $L_{d}$, and $L_{q}$, are the d-axis and q-axis inductances in the slanted air gap machine.

Since the PM flux is sufficiently strong and the rotor has a wide neutral space between the north and south poles, the original $\mathrm{d}-\mathrm{q}$ axis for the PM flux will be shifted slightly. Assuming that q-axis flux linkage is relatively small in the sine-distributed winding machine, the overall output torque equation is

$$
\begin{aligned}
T & =\frac{m}{2} p\left(\lambda_{d, P M} i_{q}+\left(L_{d^{\prime}}-L_{q^{\prime}}\right) i_{d+\alpha} i_{q+\alpha}\right) \\
& =\frac{m}{2} p\left(\lambda_{d, P M} I \sin \theta+\left(L_{d^{\prime}}-L_{q^{\prime}}\right) I^{2} \sin 2(\theta+\alpha)\right)
\end{aligned},
$$

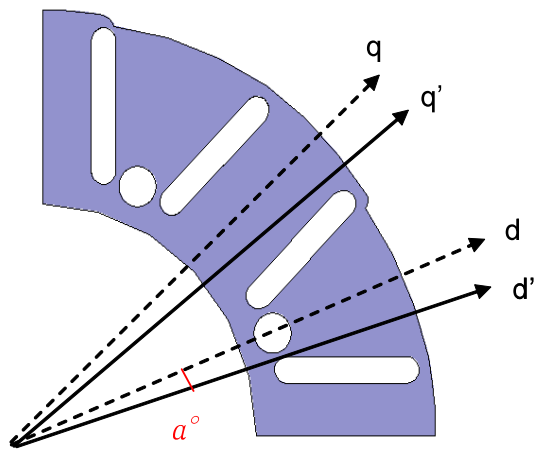

Fig. 1. Example rotor with slanted air-gap.

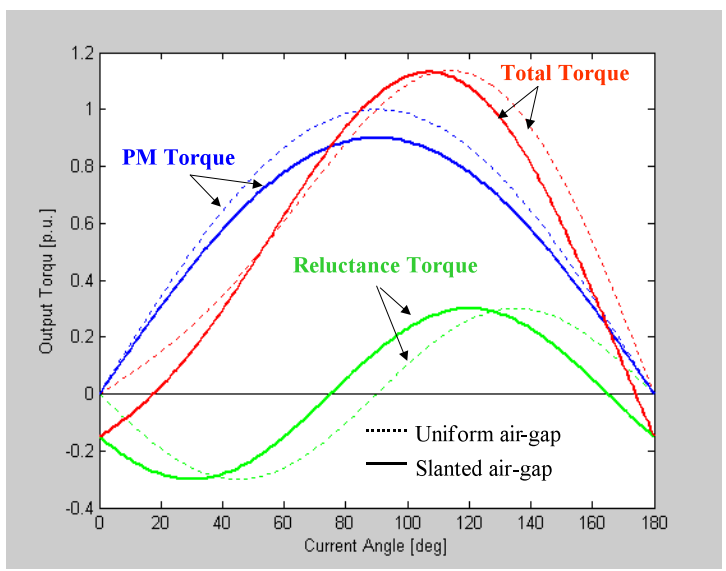

Fig. 2. Expected output torque of slanted air-gap in Fig. 1. where $\theta$ is the current angle with respect to the $+\mathrm{d}$-axis on the current $\mathrm{d}-\mathrm{q}$ plane, and $I$ is the peak current. Equation (3) indicates that the maximum value of the reluctance torque will be shifted from $135^{\circ}$ toward $90^{\circ}$ with the angle of $\alpha$ as illustrated in Fig. 2. Fig. 2 also shows that the maximum value of the total output torque is little changed, although the slanted air-gap has lower PM torque. The illustration of the slanted air-gap torque in Fig. 2 is based on smaller PM torque with the same amount of reluctance torque compared with those of the uniform air-gap.

Since slanted air-gap is expected to produce a higher reluctance torque than the uniform air-gap by decreasing the d-axis flux path, the total output torque of the slanted air-gap will be higher than that of the uniform air-gap. The simulations and experimental results which are shown in later sections prove this expectation.

\section{BRUSHLESS FIELD EXCITATION}

The brushless field excitation (BFE) structure is devised to control the magnitude of the air-gap flux by using a threedimensional magnetic rotor flux as shown in Fig. 3

Using the BFE structure, the air-gap flux of a traditional radial-gap IPMSM can be enhanced by axial-direction flux from the sides of the rotor. This excited flux travels through only the d-axis as shown in Fig. 4. As a result, the air-gap flux will be increased, and then the motor torque will also increase at a given stator current. Because a DC current controls the intensity of the axial-direction flux, the air-gap flux can decrease for the high-speed operation. The details are presented in $[3-6,12]$.

\section{ANALYZING VARIOUS SLANTED AIR-GAP SHAPES}

Although the slanted air-gap structure will be effective theoretically, how to determine the slanted depth and width is an important consideration. For this purpose, various slanted air-gap shapes have been analyzed. Fig. 5 shows the slanted air-gap shapes that were indented linearly with different depth $(h)$ and width $(l)$ between the vertical permanent magnets in the rotor.

A new output torque calculation method using a 2dimensional network magnetic equivalent circuit is applied to obtain the expected output torque along with the various slanted shapes because a conventional torque calculation method using a magnetic equivalent circuit can show only the magnitude of the reluctance torque and not the position [7, 12, 13]. Although the expected output torque shape can be obtained by FEA, it takes a significant amount of computational time to consider many different slanted air-gap shapes.

The air-gap length of the equivalent circuit is varied to meet the different slanted shapes. The variation of the slanted width has 4 different cases: (1) a quarter span between the vertical permanent magnets, (2) a half span, (3) three quarters 


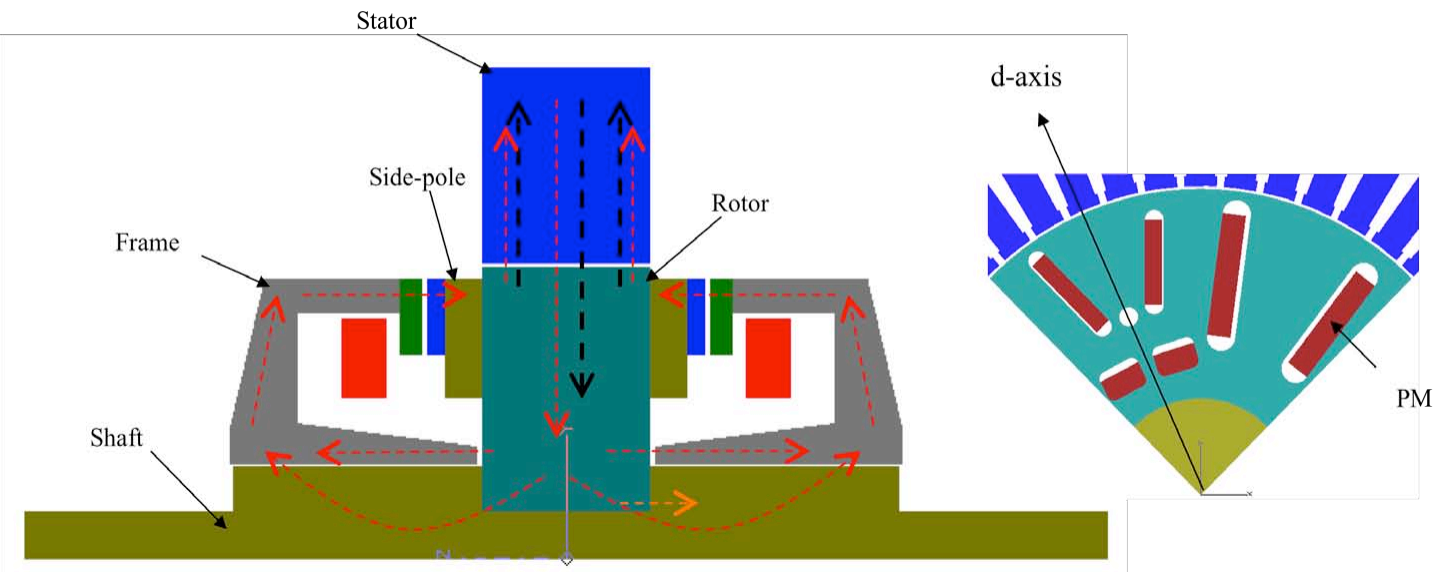

Fig. 3. Flux paths of the Brushless Field Excitation (BFE) concept.

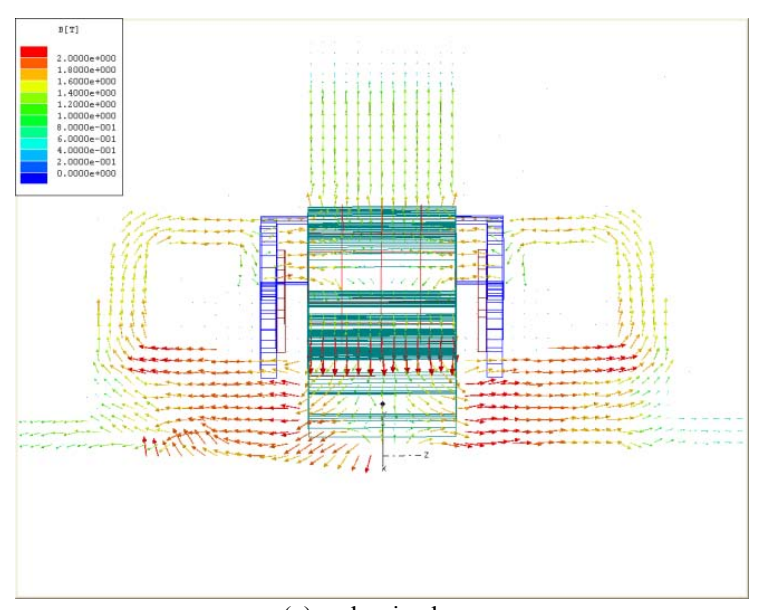

(a) d-axis plane

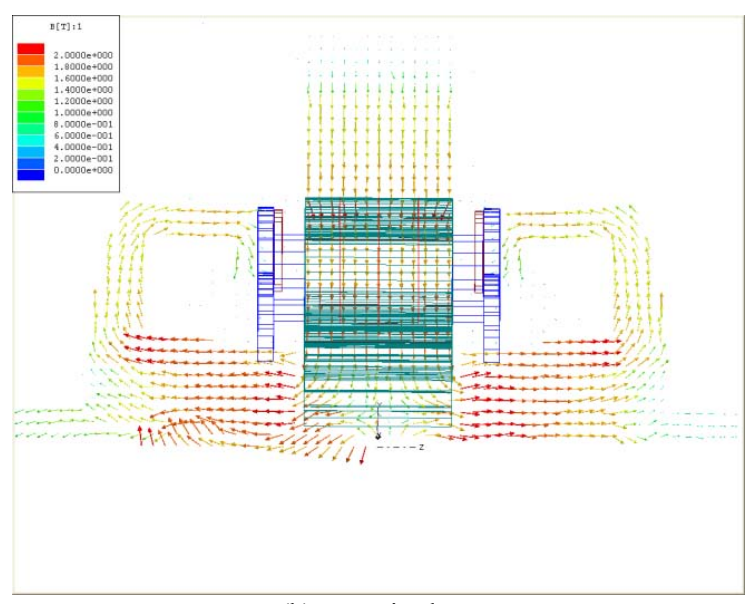

(b) q-axis plane

Fig. 4 Simulation results showing the flux flows by BFE. span, and (4) a full span. The depth is varied from $0.5 \mathrm{~mm}$ to $4.0 \mathrm{~mm}$ with a step of $0.5 \mathrm{~mm}$

The analytical comparison works are focused on three performance measures: (1) reluctance torque, (2) maximum torque, and (3) back emf ratio between $5000 \mathrm{AT}$ and $0 \mathrm{AT}$ of the excitation current. Fig. 6 is the comparison of the calculated reluctance torque. As expected, the reluctance torque increases with increasing depth at any slant width. And, the reluctance torque can be maximized when the slant width is a half span in any condition of the slant depth. Consequently, the expected maximum output torque is highlighted with a half span of the slant width, but the value decreases when the slant depth increases more than $2.5 \mathrm{~mm}$ as shown in Fig. 7. The reason presumes that the increased reluctance torque could not compensate the reduced PM torque when the slant depth reaches more than $2.5 \mathrm{~mm}$.

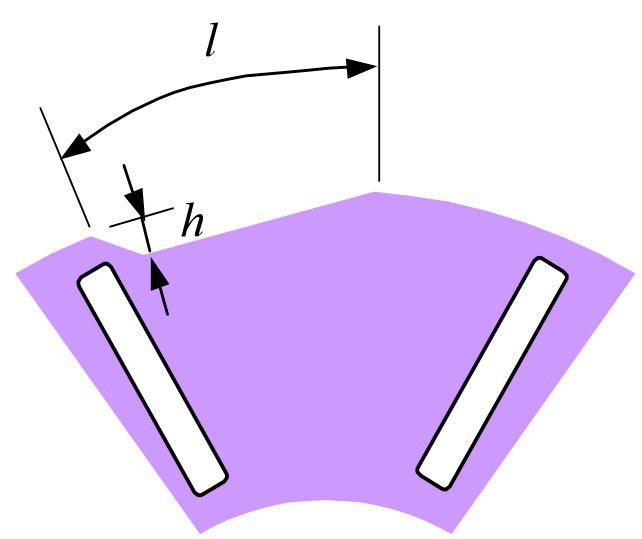

Fig. 5 An example of the slanted air-gap shape. 
Fig. 8. illustrates the expected back emf ratio of different slanted air-gap shapes. The expected value increases significantly as the rotor is slanted in large area in both depth and width. Fig. 6 also shows that the overall back emf ratio value is not sufficiently high, less than 2.5 . Therefore, to achieve a higher ratio, there must be an improvement on the excited flux path, not only the slant shape.

To verify the results from the equivalent circuit analysis, slant shapes with $2.5 \mathrm{~mm}$ of slant depth were simulated by FEA. The reason of choosing $2.5 \mathrm{~mm}$ of slant depth is that the output torque can be maximized at this depth with any slant width as shown in Fig. 7.

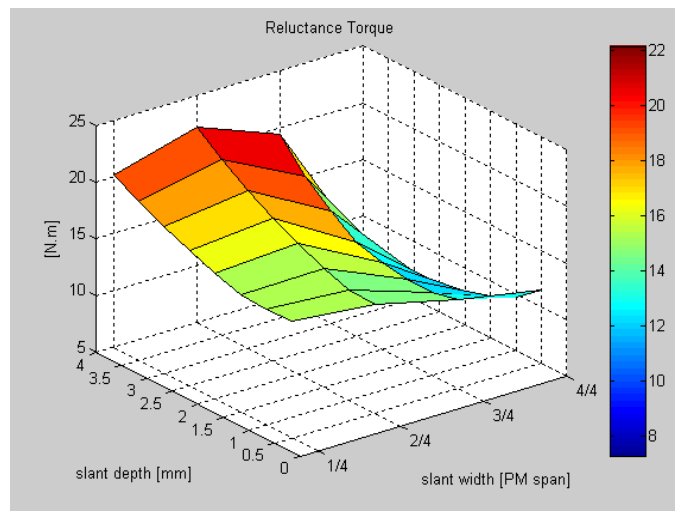

Fig. 6. Comparison of the reluctance torque versus slant width and depth.

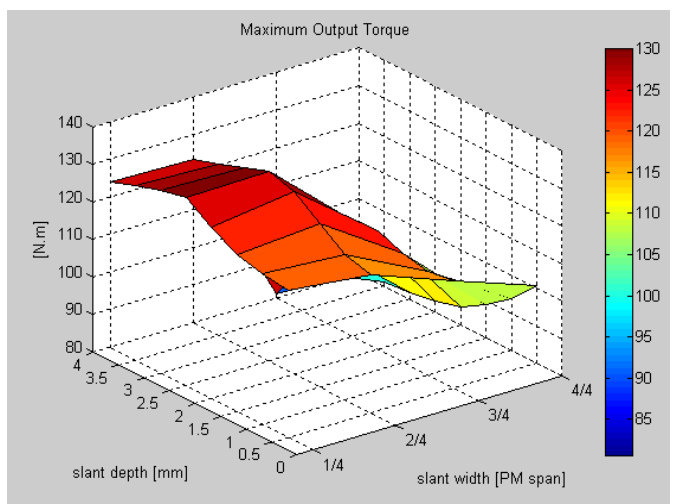

Fig. 7. Comparison of the total output torque versus slant width and depth.

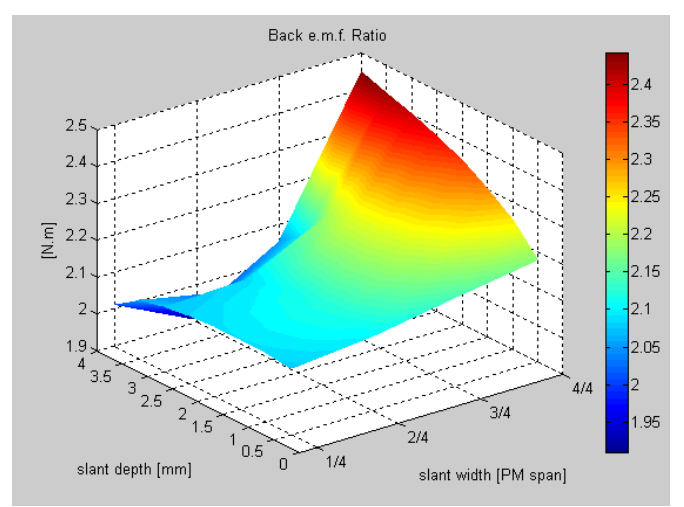

Fig. 8. Comparison of the back emf ratio versus slant width and depth.
Fig. 9 is the comparison of the calculated output torque with 5000 AT of the excitation current condition between the analytical and FEA methods. Both plots show that the maximum torque position is moved to the left side by increasing the slant width from $1 / 4$ to $3 / 4$.

Table 1 is the comparison of the computation results between the two methods in terms of the output torque and back emf ratio. There is a good match between analytical and FEA methods in terms of the output torque calculations. Also, it is clear that by using slanted air-gap structure the output torque can increase compared to uniform air-gap. These results suggest that the slant structure can be applied to the conventional type IPMSM to get high torque density.

Although there is some difference in the absolute values of the back emf ratio between the two methods, the overall trend of the variation is similar in both computation results of the maximum torque and back emf ratio. Therefore, the equivalent circuit analysis can be used for determining the machine characteristics dependence on the slant structure.

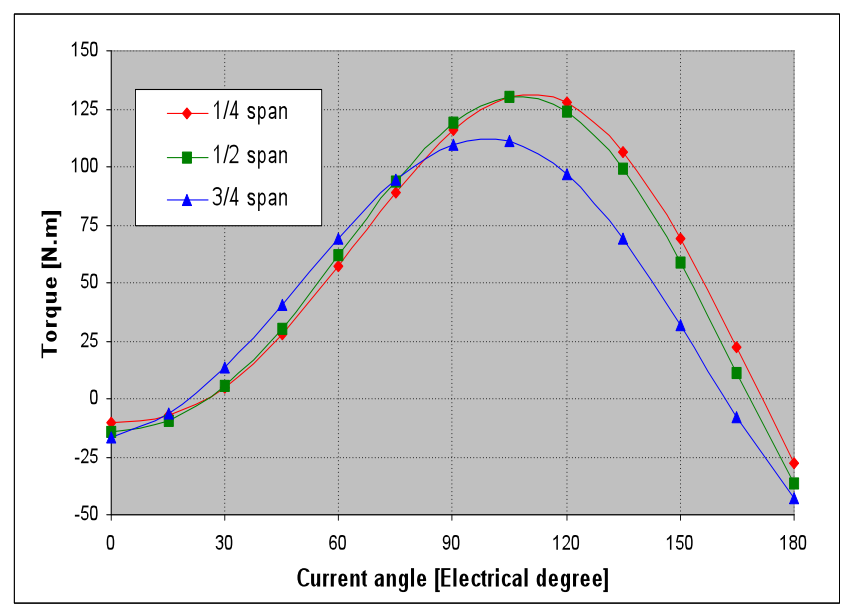

(a) Analytical method

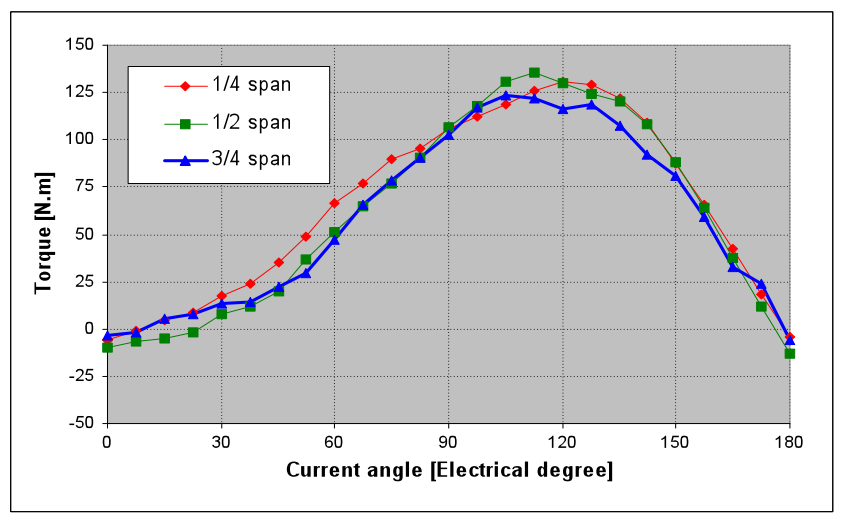

(b) FEA method

Fig. 9. Output torque calculation at 5000AT of the excitation current with different slant width and $2.5 \mathrm{~mm}$ depth. 
TABLE I.

Comparison of analytical and FEA results in various slanted air-gap models

\begin{tabular}{|c|c|c|c|}
\hline & Slanted shape & FEA & $\begin{array}{c}\text { Equivalent } \\
\text { Circuit }\end{array}$ \\
\hline \multirow{4}{*}{$\begin{array}{l}\text { Maximum } \\
\text { torque }\end{array}$} & Uniform & $121.51 \mathrm{Nm}$ & $119.26 \mathrm{Nm}$ \\
\hline & $1 / 4$ span & $\begin{array}{c}130.40 \mathrm{Nm} \\
(+7.3 \%)\end{array}$ & $\begin{array}{c}130.18 \mathrm{Nm} \\
(+9.2 \%)\end{array}$ \\
\hline & $1 / 2$ span & $\begin{array}{c}135.72 \mathrm{Nm} \\
(+11.7 \%)\end{array}$ & $\begin{array}{c}130.58 \mathrm{Nm} \\
(+9.5 \%)\end{array}$ \\
\hline & $3 / 4$ span & $\begin{array}{c}123.14 \mathrm{Nm} \\
(+1.3 \%)\end{array}$ & $\begin{array}{c}111.19 \mathrm{Nm} \\
(-6.8 \%)\end{array}$ \\
\hline \multirow{4}{*}{$\begin{array}{c}\text { Back emf } \\
\text { ratio } \\
\text { between } 0 \mathrm{AT} \\
\text { and } 5000 \mathrm{AT}\end{array}$} & Uniform & 2.26 & 2.05 \\
\hline & 1/4 span & $2.36(+4.4 \%)$ & $2.08(+1.5 \%)$ \\
\hline & $1 / 2$ span & $2.57(+13.7 \%)$ & $2.11(+2.9 \%)$ \\
\hline & $3 / 4$ span & $2.82(+24.8 \%)$ & $2.23(+8.8 \%)$ \\
\hline
\end{tabular}

* The percentage number is obtained from comparing the incremental change in the slanted shape to the values of the uniform air-gap.

\section{EXPERIMENTAL RESULTS}

From the results of the previous sections, an experimental prototype was assembled that has its slanted air-gap of 2.54 $\mathrm{mm}(0.1$ inches $)$ of the maximum depth and a half span width between two vertical PMs inside the rotor. Fig. 10 shows the assembled rotor core stack of the prototype motor. The assembled prototype of the Oak Ridge National Laboratory (ORNL) 16,000-rpm / $50 \mathrm{~kW}$ motor design is shown in Fig. 11 , which has a unique BFE structure that is explained in section IV.

Fig. 12 is the expected reluctance torque of the prototype motor when the input phase current is $200 \mathrm{~A}\left(I_{\max }=200 \mathrm{~A}\right)$. In the figure, the analysis results of the slanted air-gap motor (prototype) are compared with the motor without slanted airgap structure (uniform air-gap rotor). Fig. 12 clearly shows that the slanted air-gap structure has a higher maximum value of reluctance torque than the uniform structure for both analytical and FEA methods (42.98 Nm vs. $15.73 \mathrm{Nm}$ in analytical method, and $35.92 \mathrm{Nm}$ vs. $12.57 \mathrm{Nm}$ in FEA method). Also, the maximum reluctance torque position is shifted from $135^{\circ}$ toward $90^{\circ}$ as desired.

Fig. 13 is the expected output torque profile when input phase current is $200 \mathrm{~A}$ and the excitation current is $5 \mathrm{~A}\left(I_{\text {exc }}=\right.$ 5 A). Since the excitation coils are wound 865 turns, the total excitation condition is 4325 AT. The experimental test results are also plotted in Fig. 13, which are agreeable to the analysis results. For its increased reluctance torque as shown in Fig. 12, the slanted air-gap rotor has higher output torque than the uniform air-gap rotor.

Fig. 14 is the experimental results showing the controllable back emf voltage. The baseline waveforms in Fig. 14 are obtained at 1,000 rpm with no field excitation and enhanced

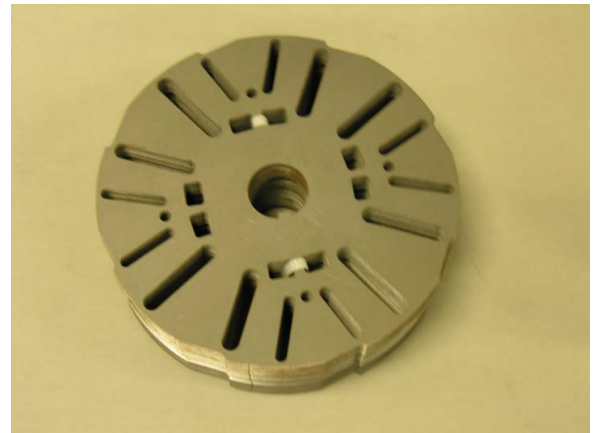

Fig. 10. Assembled rotor core stack for slanted shape PM.

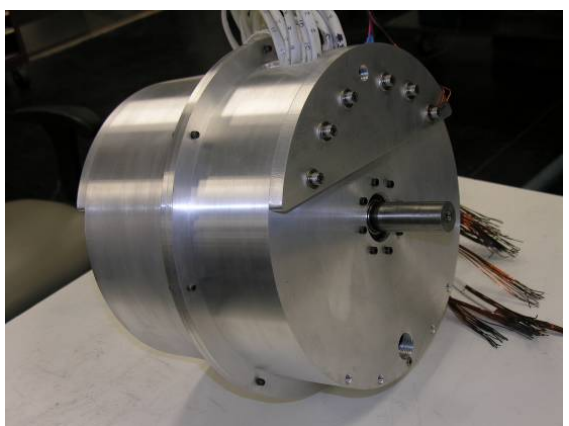

Fig. 11. Assembly of ORNL 16,000-rpm motor.

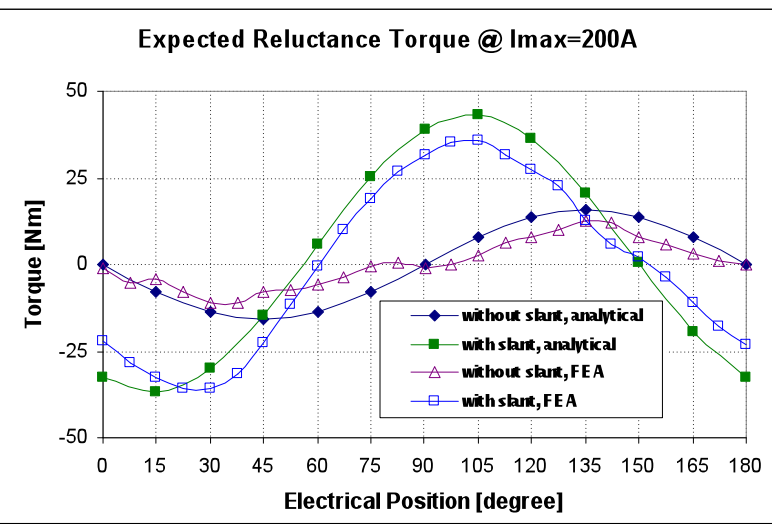

Fig. 12. Comparison of the expected reluctance torque at $I_{\max }=200 \mathrm{~A}$.

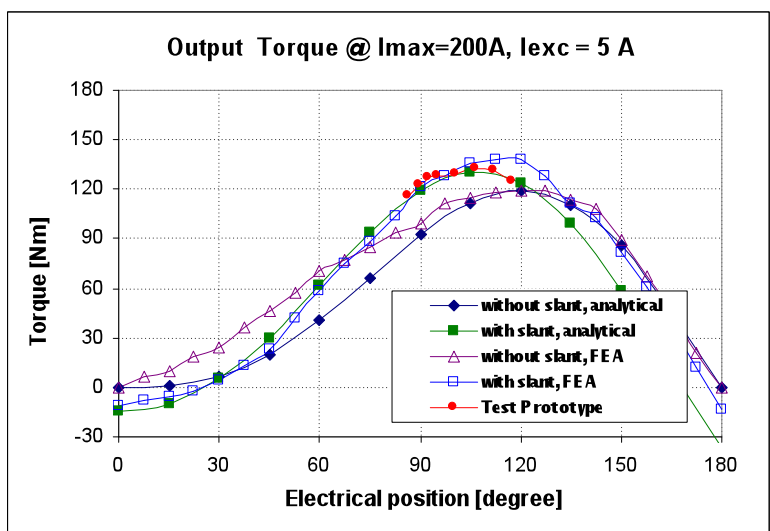

Fig. 13. Comparison of the expected output torque at $I_{\max }=200 \mathrm{~A}$. 
by a field excitation of $+5 \mathrm{~A}$. These graphs prove that the back emf voltage can be controllable by the excitation current.

Table II indicates the effect of the slanted air-gap in both output torque and back emf ratio. Although there is some difference between FEA simulation and experimental test results, it is clear that the slanted air-gap rotor has higher output torque and controllable back emf ratio.

Data points for each efficiency map were taken for speeds from $1,000 \mathrm{rpm}$ to $16,000 \mathrm{rpm}$ in $1,000 \mathrm{rpm}$ increments and from $0 \mathrm{Nm}$ increasing in $10 \mathrm{Nm}$ increments to a final high torque value at each speed. A total of six efficiency maps were generated corresponding to the excitation currents of 0 A, 1 A, 2 A, 3 A, 4 A, and 5 A. Fig. 15 shows the projected efficiency contours using optimal field current for achieving the highest efficiency by controlling the excitation current. This projected efficiency is substantially superior to the efficiency of a Toyota Prius motor which was a baseline motor for this project [4]. This higher efficiency is due to the reduced core loss by controlling air-gap flux through the BFE structure [3].

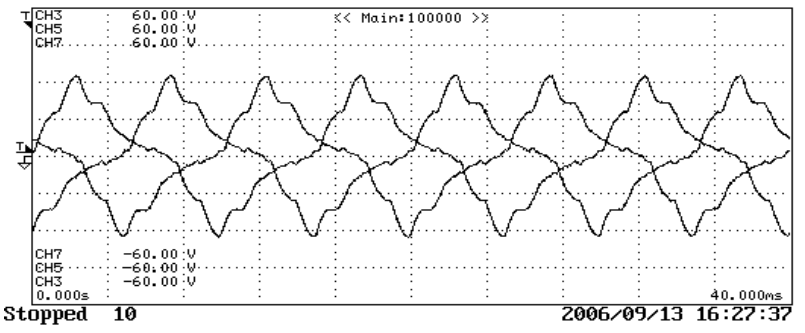

(a) No excitation field current (16.3 $\left.\mathrm{V}_{\mathrm{rms}} @ 1,000 \mathrm{rpm}\right)$

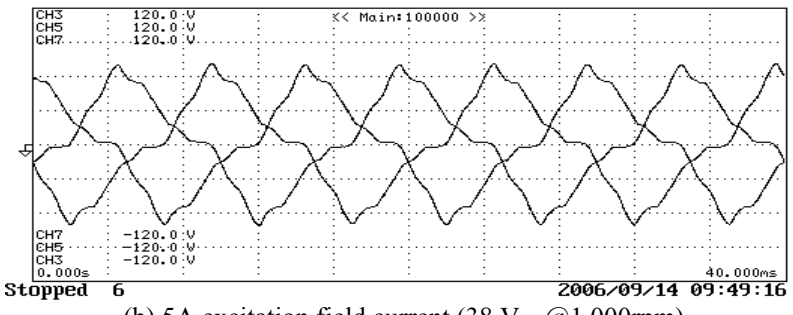

(b) $5 \mathrm{~A}$ excitation field current (38 $\left.\mathrm{V}_{\mathrm{rms}} @ 1,000 \mathrm{rpm}\right)$

Fig. 14. Comparison of the tested back emf voltage when the excitation current is $0 \mathrm{~A}$ and $5 \mathrm{~A}$.

TABLE II. Comparison of simulation results in different air-gap models

\begin{tabular}{|c|c|c|c|}
\hline & without slant & \multicolumn{2}{|c|}{ with slant } \\
\cline { 2 - 4 } & FEA & FEA & Test \\
\hline $\begin{array}{c}\text { Max. reluctance torque } \\
@ I_{\max }=200 \mathrm{~A}\end{array}$ & $12.57 \mathrm{Nm}$ & $35.71 \mathrm{Nm}$ & - \\
\hline $\begin{array}{c}\text { Max. output torque } \\
@ I_{\max }=200 \mathrm{~A}, I_{e x c}=5 \mathrm{~A}\end{array}$ & $119.41 \mathrm{Nm}$ & $138.44 \mathrm{Nm}$ & $132.45 \mathrm{Nm}$ \\
\hline Back emf * @ $I_{e x c}=5 \mathrm{~A}$ & $211.7 \mathrm{~V}$ & $182.1 \mathrm{~V}$ & $191.4 \mathrm{~V}$ \\
\hline Back emf $@ @ I_{e x c}=0 \mathrm{~A}$ & $97.1 \mathrm{~V}$ & $72.4 \mathrm{~V}$ & $80.0 \mathrm{~V}$ \\
\hline $\begin{array}{c}\text { Back emf ratio between } \\
I_{e x c}=5 \mathrm{~A} \text { and } I_{e x c}=0 \mathrm{~A}\end{array}$ & 2.18 & 2.52 & 2.39 \\
\hline * at 5000 rpm & & & \\
\hline
\end{tabular}

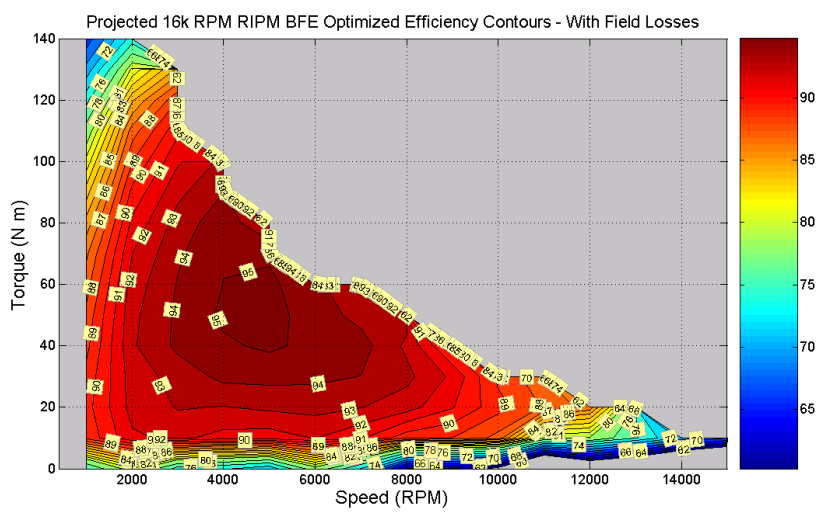

Fig. 15. Projected efficiency contours using optimal field current.

\section{CONCLUSIONS}

The experimental results of the prototype show the effects of the slanted air-gap. The summarized conclusions are as follows.

(1) The maximum torque of the slanted air-gap rotor is higher than that of the uniform air-gap rotor (without slanted air-gap) in spite of the smaller air-gap flux.

(2) The slanted air-gap is effective in obtaining a high controllable back-emf ratio from the BFE structure.

(3) The determination of the slanted air-gap shape was achieved from the magnetic equivalent circuit analysis and FEA, and the expected output torque agrees with the experimental results.

(4) The best slanted shape has a half span between two vertical PM arrangements inside the rotor.

(5) From (1) and (4), the slanted air-gap structure could be applied to a conventional IPMSM (without BFE structure) to achieve high torque density.

(6) The reduced PM flux could reduce the iron loss of the machine at high-speed operation. As a result, the overall efficiency could increase.

(7) For application of the slanted air-gap structure, it is necessary to study the harmonics in the air-gap flux caused by the unbalanced air-gap shape.

\section{REFERENCES}

[1] T. M. Jahns, "Component Rating Requirements for Wide Constant Power Operation of Interior PM Machine Drives," IEEE Industry Applications Society Annual Meeting, vol. 3, 2000, pp. 1697 - 1704.

[2] M. El-Refaie and T. M. Jahns, "Comparison of Synchronous PM Machine Type for Wide Constant-Power Speed Range Operation," IEEE Industry Applications Annual Meeting, vol. 2, 2005, pp. 1015 1022 .

[3] J. S. Hsu, T. A. Burress, S. T. Lee, R. H. Wiles, C. L. Coomer, J. W. McKeever, and D. J. Adams, "16,000-rpm Interior Permanent Magnet Reluctance Machine with Brushless Field Excitation," ORNL/TM2007/167, Oak Ridge National Laboratory, Oak Ridge, Tennessee, 2007. 
[4] J. S. Hsu, S. T. Lee, R. H. Wiles, C. L. Coomer, K. T. Lowe, and T. A. Burress, "Effect of Side Permanent Magnets for Reluctance Interior Permanent Magnet Machines," IEEE Power Electronics Specialists Conference, Jun. 2007, pp. $2267-2272$.

[5] J. S. Hsu, S. T. Lee, and L. M. Tolbert, "High-Strength Undiffused Brushless (HSUB) Machine," IEEE Industry Applications Society Annual Meeting, Oct. 2008, 8 pages.

[6] J. S. Hsu, T. A. Burress, S. T. Lee, R. H. Wiles, C. L. Coomer, J.W. McKeever, and D. J. Adams, "16,000-RPM Interior Permanent Magnet Reluctance Machine with Brushless Field Excitation," IEEE Industry Applications Society Annual Meeting, Oct. 2008, 6 pages.

[7] S. T. Lee and L. M. Tolbert, "Analysis of Slanted Air-gap Structure of Interior Permanent Magnet Synchronous Motor with Brushless Field Excitation," IEEE Energy Conversion Congress and Exposition, Sep. 2009, pp. 126-131.

[8] T. J. E. Miller, Brushless Permanent-Magnet and Reluctance Motor Drives, London, Clarendon Press, 1989.
[9] S. A. Nasar, I. Boldea, and L. E. Unnewehr, Permanent Magnet, Reluctance, and Self-Synchronous Motors, CRC Press Inc., United States, 1993.

[10] M. A. Rahman, P. Zhou, "Analysis of Brushless Permanent Magnet Synchronous Motors," IEEE Transactions on Industrial Electronics, vol. 43, no. 2, 1996, pp. 256-267.

[11] I. Boldea, L. Tutelea, and C. I. Pitic, "PM-Assisted Reluctance Synchronous Motor/Generator (PM-RSM) for Mild Hybrid Vehicles: Electromagnetic Design," IEEE Transactions on Industry Applications, vol. 40, no. 2, March-April 2004, pp. $492-498$.

[12] S. T. Lee, "Development and Analysis of Interior Permanent Magnet Synchronous Motor with Field Excitation Structure," Ph. D. Dissertation, Min Kao Department of Electrical Engineering and Computer Science, Univ. Tennessee, Knoxville, August 2009.

[13] S. T. Lee and L. M. Tolbert, "Analytical Method of Torque Calculation for Interior Permanent Magnet Synchronous Machines," IEEE Energy Conversion Congress and Exposition, Sep. 2009, pp. 173-177. 